\title{
Soil Stabilization By Using Fly Ash
}

\author{
Karthik.S ${ }^{1}$, Ashok kumar.E ${ }^{2}$, Gowtham.P ${ }^{2}$, Elango.G ${ }^{2}$, Gokul.D ${ }^{2}$, Thangaraj.S ${ }^{2}$ \\ Assistant Professor, Department of Civil engineering, Jay Shriram Group of Institutions, Avinashipalayam, \\ Tirupur, Tamilnadu, India. \\ Under graduate students, Department of Civil engineering, Jay Shriram Group of Institutions, \\ Avinashipalayam, Tirupur, Tamilnadu, India
}

\begin{abstract}
Soil is a peculiar material. Some waste materials such Fly Ash, rice husk ash, pond ash may use to make the soil to be stable. Addition of such materials will increase the physical as well as chemical properties of the soil. Some expecting properties to be improved are CBR value, shear strength, liquidity index, plasticity index, unconfined compressive strength and bearing capacity etc. The objective of this study was to evaluate the effect of Fly Ash derived from combustion of sub-bituminous coal at electric power plants in stabilization of soft fine-grained red soils. California bearing ratio $(C B R)$ and other strength property tests were conducted on soil. The soil is in range of plasticity, with plasticity indices ranging between 25 and 30. Tests were conducted on soils and soil-Fly Ash mixtures prepared at optimum water content of 9\%.Addition of Fly Ash resulted in appreciable increases in the CBR of the soil. For water contents 9\% wet of optimum, CBRs of the soils are found in varying percentage such that 3,5,6and 9. We will found optimum CBR value of the soil is 6\%.Increment of CBR value is used to reduce the thickness of the pavement. And increasing the bearing capacity of soil.
\end{abstract}

\section{Introduction}

Aim of this research is to stabilize the locally available red soil around tirupur district. The stabilization is done for the following reasons.

Soil stabilisation is widely used in connection with road, pavement and foundation construction.

It improves the engineering properties of the soil, e.g:

* Strength - to increase the strength and bearing capacity,

* Volume stability - to control the swell-shrink characteristics caused by moisture changes,

* Durability - to increase the resistance to erosion, weathering or traffic loading.

* To reduce the pavement thickness as well as cost.

According to the selected sight the traffic type is guessed as ' $\mathrm{A}$ '. Pavement thickness according to the CBR values are estimated and compared to expose the economic impact of soil stabilization by using Fly Ash.

\section{Literature Review}

Fly Ash by itself has little cementatious value but in the presence of moisture it reacts chemically and forms cementatious compounds and attributes to the improvement of strength and compressibility characteristics of soils. It has a long history of use as an engineering material and has been successfully employed in geotechnical applications.

Erdal Cokca (2001): Effect of Fly Ash on expansive soil was studied by Erdal Cokca,FLY ASH consists of often hollow spheres of silicon, aluminium and iron oxides and unoxidized carbon. There 1 Research Scholar,eshwari_28@yahoo.co.in 2 Assistant Professor, robinson@iitm.ac.in 3. Professor, srgandhi@iitm.ac.in Indian Institute of Technology Madras, Chennai-36 .Fly Ash India 2005, New Delhi Fly Ash Utilization Programme (FAUP), TIFAC, DST, New Delhi - 110016 are two major classes of Fly Ash, class C and class F. The former is produced from burning anthracite or bituminous coal and the latter is produced from burning lignite and sub bituminous coal. Both the classes of Fly Ash are puzzolans, which are defined as siliceous and aluminous materials. Thus Fly Ash can provide an array of divalent and trivalent cations $(\mathrm{Ca} 2+, \mathrm{Al} 3+, \mathrm{Fe} 3+\mathrm{etc})$ under ionized conditions that can promote flocculation of dispersed clay particles. Thus expansive soils can be potentially stabilized effectively by cation exchange using Fly Ash. He carried out investigations using Soma Fly Ash and Tuncbilek Fly Ash and added it to expansive soil at 0-25\%. Specimens with Fly Ash were cured for 7 days and 28 days after which they were subjected to Oedometer free swell tests. And his experimental findings confirmed that the plasticity index, activity and swelling potential of the samples decreased with increasing percent stabilizer and curing time and the optimum content of Fly Ash in decreasing the swell potential was found to be $20 \%$. The changes in the physical properties and swelling potential is a result of additional silt size particles to some extent and due to chemical reactions that cause immediate flocculation of clay particles and the time dependent puzzolanic and self hardening properties of Fly Ash and he concluded that both high -calcium and low calcium class C Fly Ashes can be recommended as effective stabilizing agents for improvement for improvement of expansive soils. 


\section{S.Bhuvaneshwari and S.R. Gandhi:}

A study was carried out by S.Bhuvaneshwari and S.R. Gandhi on the effect of engineering properties of expansive soil through an experimental programme.

Infrastructure projects such as highways, railways, water reservoirs, reclamation etc. requires earth material in very large quantity. In urban areas, borrow earth is not easily available which has to be hauled from a long distance. Quite often, large areas are covered with highly plastic and expansive soil, which is not suitable for such purpose. Extensive laboratory / field trials have been carried out by various researchers and have shown promising results for application of such expansive soil after stabilization with additives such as sand, silt, lime, Fly Ash, etc. As Fly Ash is freely available, for projects in the vicinity of a Thermal Power Plants, it can be used for stabilization of expansive soils for various uses. The present paper describes a study carried out to check the improvements in the properties of expansive soil with Fly Ash in varying percentages. Both laboratory trials and field tests have been carried out and results are reported in this paper. One of the major difficulties in field application is thorough mixing of the two materials (expansive soil and Fly Ash) in required proportion to form a homogeneous mass. The paper describes a method adopted for placing these materials in layers of required thickness and operating a "Disc Harrow". A trial embankment of $30 \mathrm{~m}$ length by $6 \mathrm{~m}$ width by $0.6 \mathrm{~m}$ high was successfully constructed and the in-situ tests carried out proved its suitability for construction of embankment, ash dykes, filling low-laying areas, etc.

Pandian et.al. (2002). Studied the effect of two types of Fly Ashes Raichur Fly Ash (Class F) and Neyveli Fly Ash (Class C) on the CBR characteristics of the black cotton soil. The Fly Ash content was increased from 0 to $100 \%$. Generally the CBR/strength is contributed by its cohesion and friction. The CBR of BC soil, which consists of predominantly of finer particles, is contributed by cohesion. The CBR of Fly Ash, which consists predominantly of coarser particles, is contributed by its frictional component. The low CBR of BC soil is attributed to the inherent low strength, which is due to the dominance of clay fraction. The addition of Fly Ash to $\mathrm{BC}$ soil increases the CBR of the mix up to the first optimum level due to the frictional resistance from Fly Ash in addition to the cohesion from BC soil. Further addition of Fly Ash beyond the optimum level causes a decrease up to $60 \%$ and then up to the second optimum level there is an increase. Thus the variation of CBR of Fly Ash-BC soil mixes can be attributed to the relative contribution of frictional or cohesive resistance from Fly Ash or BC soil, respectively. In Neyveli Fly Ash also there is an increase of strength with the increase in the Fly Ash content, here there will be additional puzzolonic reaction forming cementitious compounds resulting in good binding between BC soil and Fly Ash particles

Phanikumar and Sharma (2004): A similar study was carried out by Phanikumar and Sharma and the effect of Fly Ash on engineering properties of expansive soil through an experimental programme. The effect on parameters like free swell index (FSI), swell potential, swelling pressure, plasticity, compaction, strength and hydraulic conductivity of expansive soil was studied. The ash blended expansive soil with FLY ASH contents of $0,5,10,15$ and $20 \%$ on a dry weight basis and they inferred that increase in FLY ASH content reduces plasticity characteristics and the FSI was reduced by about $50 \%$ by the addition of $20 \%$ Fly Ash. The hydraulic conductivity of expansive soils mixed with Fly Ash decreases with an increase in Fly Ash content, due to the increase in maximum dry unit weight with an increase in Fly Ash content. When the Fly Ash content increases there is a decrease in the optimum moisture content and the maximum dry unit weight increases. The effect of Fly Ash is akin to the increased compactive effort. Hence the expansive soil is rendered more stable. The untrained shear strength of the expansive soil blended with Fly Ash increases with the increase in the ash content.

The following laboratory tests were carried out as per IS: 2720.The test were carried out on both normal soil and stabilized soil.

1. Specific gravity test

2. Grain size analysis

3. Atterbegs limits

4. Proctor compaction test

5. California Bearing Ratio value $(\mathrm{CBR})$ test

6. Un Confined Compressive strength (UCC) test

$7 . \quad$ Direct shear test

8. North Dakota test

After removing impurities like vegetation, stones etc. the soil was mixed with Fly Ash in varying proportion by volume. The Mixing was thoroughly carried out manually and the tests were conducted as per standard procedures. 
Atterberg's limits

Analysis of lab tests:

The liquid limit of the soil with varying percentage of Fly Ash is given in table 1 and fig 1

Table 1: LIQUID LIMIT VALUES FOR SOIL WITH FLY ASH

\begin{tabular}{|ll|l|}
\hline $\begin{array}{l}\text { \% OF } \\
\text { ASH }\end{array}$ & FLY & LIQUID LIMIT (\%) \\
\hline 0 & & 32 \\
\hline 3 & & 30 \\
\hline 5 & 25 \\
\hline 6 & 27 \\
\hline 9 & & 23 \\
\hline
\end{tabular}

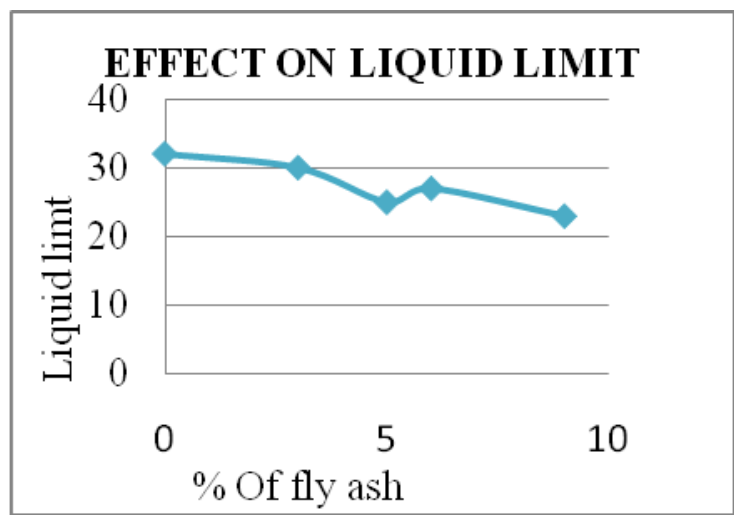

Fig 1: LIQUID LIMIT DISTRIBUTION CURVE FOR FLY ASH

The plastic limit of the soil with varying percentage of Fly Ash is given in table 2 and fig 2

Table 2: PLASTIC LIMIT VALUES FOR FLY ASH

\begin{tabular}{|l|c|}
\hline \% OF & PLASTIC LIMIT (\%) \\
FLY ASH & 23.37 \\
\hline 0 & 25 \\
\hline 3 & 13.7 \\
\hline 5 & 18 \\
\hline 6 & 14 \\
\hline 9 & \\
\hline
\end{tabular}

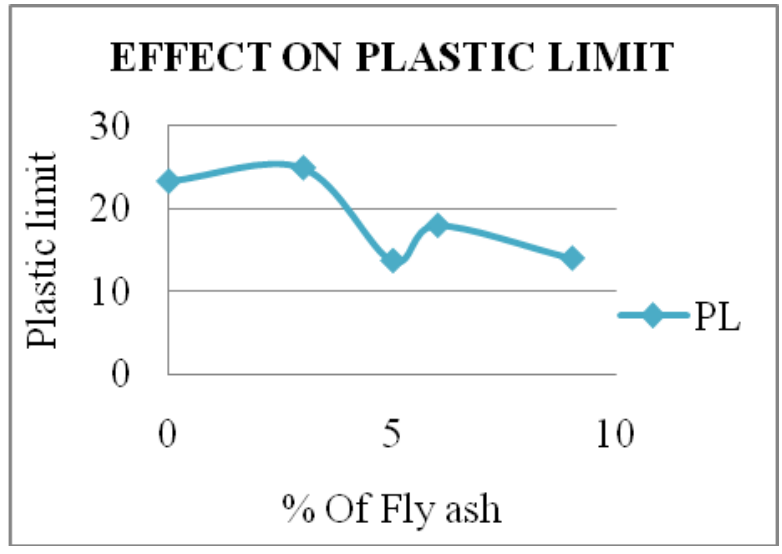

Fig 2: PLASTIC LIMIT DISTRIBUTION CURVE FOR FLY ASH

Specific gravity

The specific gravity of the soil with varying percentage of Fly Ash is given in table 3 and fig 3 $\mathrm{S}=\frac{(\mathrm{M} 2-\mathrm{M} 1)}{(\mathrm{M} 4-\mathrm{M} 1)-(\mathrm{M} 3-\mathrm{M} 2)}$ 
Table 3: SPECIFIC GRAVITY VALUES FOR FLY ASH

\begin{tabular}{|c|c|}
\hline \% OF FLY ASH & SPECIFIC GRAVITY \\
\hline 0 & 2.7 \\
\hline 3 & 2.6 \\
\hline 5 & 2.8 \\
\hline 6 & 2.7 \\
\hline 9 & 2.7 \\
\hline
\end{tabular}

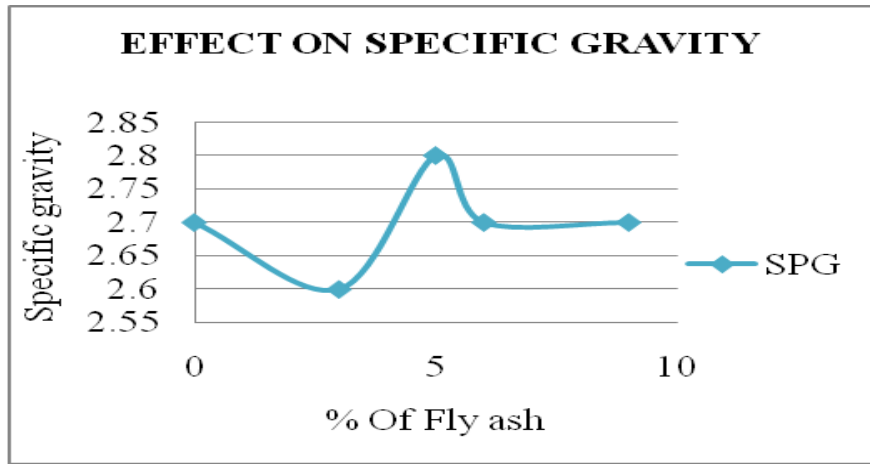

Fig 3. SPECIFIC GRAVITY CURVE FOR SOIL WITH FLY ASH

Proctor compaction test

The OMC of the soil with varying percentage of Fly Ash is given in table 3 and fig 3

Table 3: OMC VALUES FOR FLY ASH

\begin{tabular}{|c|c|}
\hline $\begin{array}{c}\text { \% Of } \\
\text { Fly Ash }\end{array}$ & $\begin{array}{c}\text { O.M.C } \\
(\%)\end{array}$ \\
\hline 0 & 8.9 \\
\hline 3 & 9 \\
\hline 5 & 8.2 \\
\hline 6 & 10.2 \\
\hline 9 & 9.3 \\
\hline
\end{tabular}

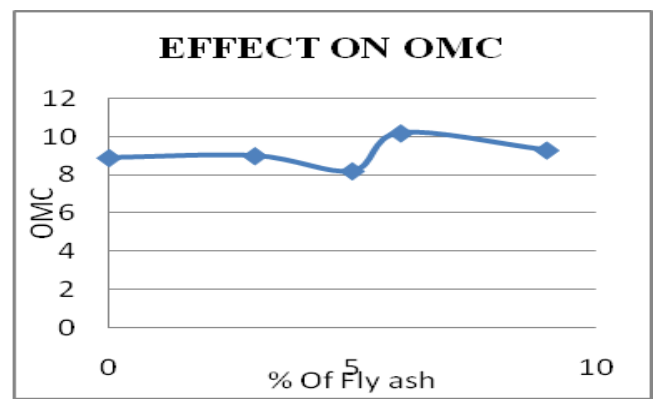

Fig3: OMC CURVE FOR FLY ASH

\section{Maximum dry density}

The maximum dry density of the soil with varying percentage of Fly Ash is given in table 4 and fig 4

Table 4: MAXIMUM DRY DENSITY VALUES FOR FLY ASH

\begin{tabular}{|c|c|}
\hline $\begin{array}{c}\text { \% Of } \\
\text { Fly Ash }\end{array}$ & Maximum dry density $* 10^{\wedge} 3(\mathrm{Kg} / \mathrm{m} 3)$ \\
\hline 0 & 2.11 \\
\hline 3 & 2.07 \\
\hline 5 & 2.31 \\
\hline 6 & 2.35 \\
\hline 9 & 2.21 \\
\hline
\end{tabular}




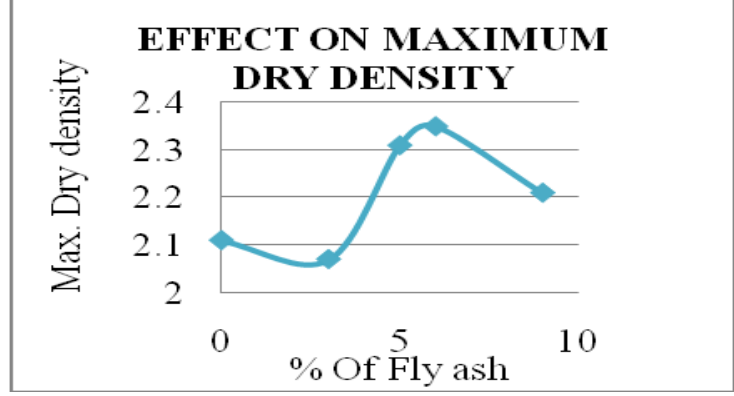

Fig 4: MDD CURVE FOR FLY ASH

CBR- California Bearing Ratio

The CBR of the soil with varying percentage of Fly Ash is given in table 5 and fig 5

Table 5 CBR VALUES at $2.5 \mathrm{~mm}$ deflection

\begin{tabular}{|c|c|}
\hline$\%$ Of & CBR VALUE@ \\
Fly Ash & $2.5 \mathrm{~mm}$ \\
\hline 0 & 2.08 \\
\hline 3 & 1.56 \\
\hline 5 & 1.51 \\
\hline 6 & 3.75 \\
\hline 9 & 2.13 \\
\hline
\end{tabular}

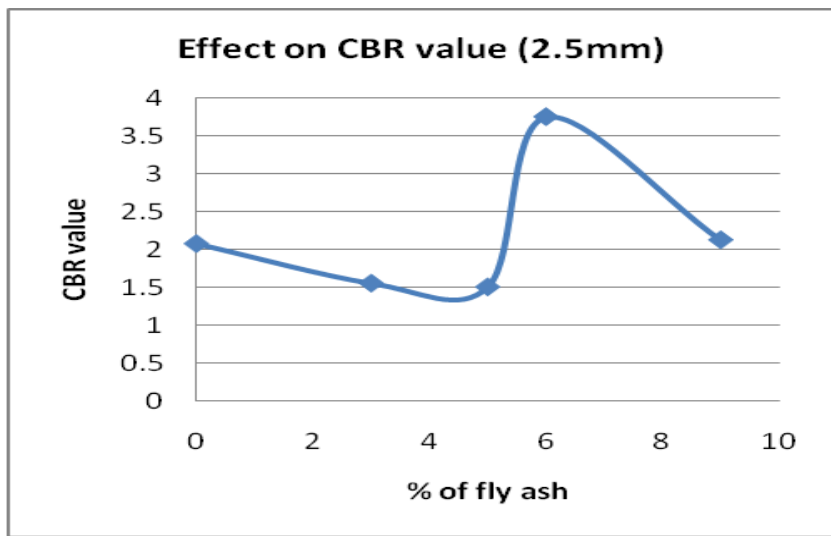

Fig 5 CBR CURVE FOR FLY ASH

Table 6: CBR VALUES at 5mm deflection

\begin{tabular}{|c|c|}
\hline$\%$ Of & CBR VALUE@ \\
Fly Ash & $5 \mathrm{~mm}$ \\
\hline 0 & 3.1 \\
\hline 3 & 2.9 \\
\hline 5 & 3.12 \\
\hline 6 & 4.82 \\
\hline 9 & 3.03 \\
\hline
\end{tabular}

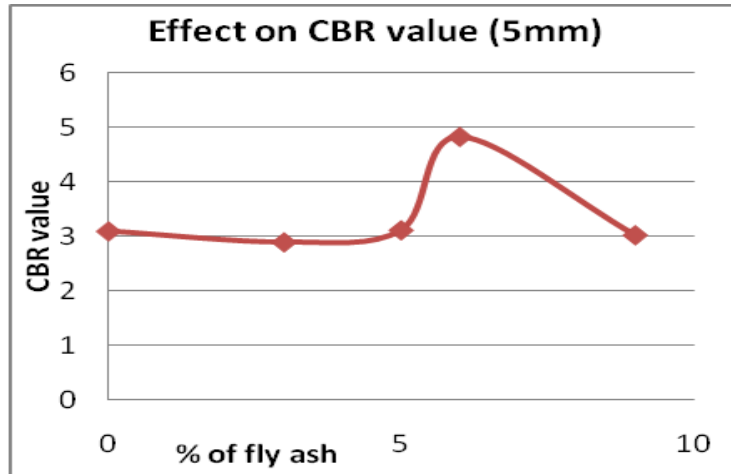

Fig 6. CBR CURVE FOR FLY ASH 
Unconfined compression test

The UCC of the soil with varying percentage of Fly Ash is given in table 7 and fig 7

Table7: UCC VALUES FOR FLY ASH

\begin{tabular}{|c|c|}
\hline $\begin{array}{c}\text { Of } \\
\text { Fly Ash }\end{array}$ & UCC (N/cm2) \\
\hline 0 & 3.881840 \\
\hline 3 & 4.100000 \\
\hline 5 & 4.440923 \\
\hline 6 & 8.881850 \\
\hline 9 & 4.885015 \\
\hline
\end{tabular}

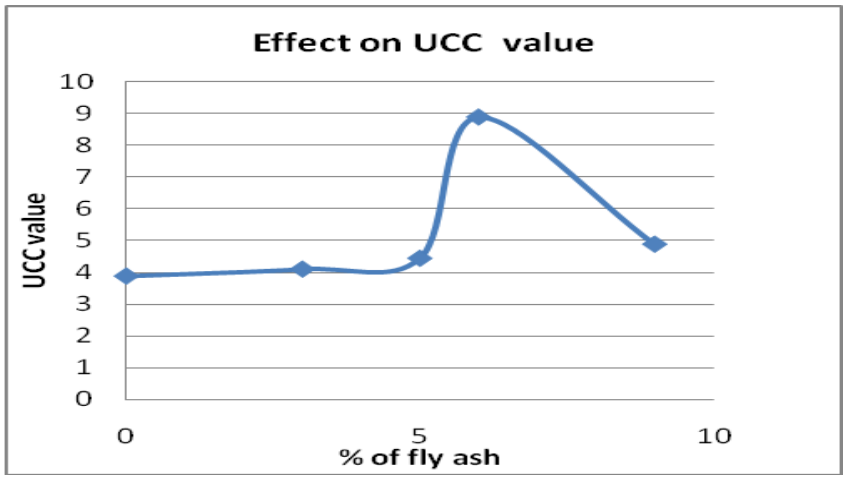

Fig 7. UCC CURVE FOR FLY ASH

North Dakota value test

The North Dakota of the soil with varying percentage of Fly Ash is given in table 9 and fig 9

Table8: NORTH DOKOTA VALUES FOR FLY ASH

\begin{tabular}{|c|c|}
\hline \% of Fly Ash & Bearing capacity $(\mathrm{kg} / \mathrm{mm} 2)$ \\
\hline 0 & 10.93 \\
\hline 3 & 8.75 \\
\hline 5 & 17.2 \\
\hline 6 & 35.06 \\
\hline 9 & 12.27 \\
\hline
\end{tabular}

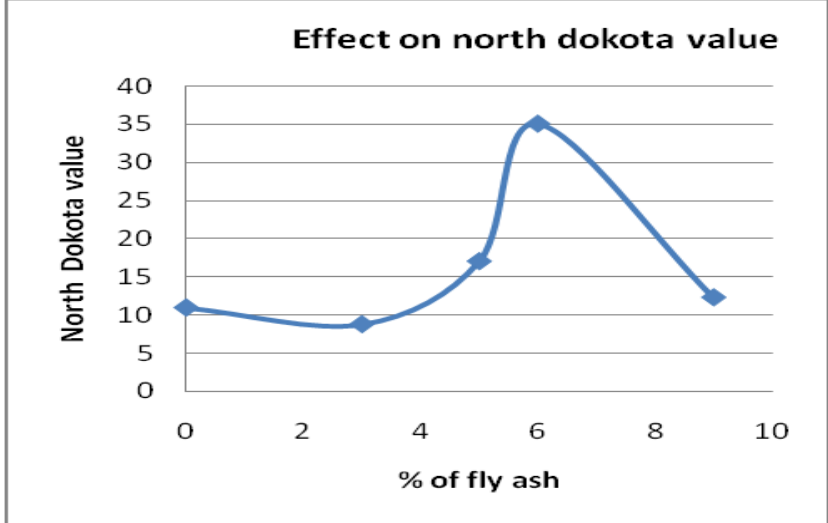

Fig 8. NORTH DOKOTA CURVE FOR FLY ASH

\section{Conclusions:}

Based on the data accumulated from above research following conclusions have been made.

- $\quad$ The borrowed red soil has bearing capacity of $10 \mathrm{~kg} / \mathrm{mm}^{2}$.

- The stabilized red soil with 6 percentage of Fly Ash achieves bearing capacity of $35 \mathrm{~kg} / \mathrm{mm}^{2}$

- The CBR value of borrowed red soil is 3.1. From design curvein 'A' type traffic, pavement thickness for corresflying soil is 12 inches.

- $\quad$ CBR value of stabilized soil is 4.82. Pavement thickness corresflying to this value is8.5inches. 


\section{Acknowledgement}

The authors would like to express an acknowledgement to the Faculty of R.GOPINATH Head of Civil Engineering and management of jay shri ram groups of institutions tirupur, for providing the facilities such as the geotechnical laboratory and advanced geotechnical laboratory to accomplish this study. The author also wishes to acknowledge cooperation given by laboratory technician from Faculty of Civil Engineering, jay shri ram groups of instutions, tirupur to complete this study.

\section{References:}

[1]. Chen, F. H. (1988), "Foundations on expansive soils", Chen \& Associates, Elsevier Publications, U.S.A.

[2]. Erdal Cokca (2001) "Use Of Class C Fly Ashes for the Stabilization - of an Expansive Soil" Journal of Geotechnical and Geo environmental Engineering Vol. 127, July, pp. 568-573.

[3]. Eldon J. Yoder(1957), "Principles of Soil Stabilization",JHRPPublicationIndiana.

[4]. Pradip D. Jadhao and Nagarnaik, P.B (2008), Influence of Polypropylene Fibres on Engineering Behavior of Soil - Fly Ash Mixtures for Road Construction, Electronic Journal of Geotechnical Engineering, Vol. 13, Bund.C, pp. 1-11.

[5]. 1.American Society for Testing and Materials, ASTM C618 (2008) Specification for Fly Ash and Raw or Calcined Natural Pozzolanic for Use as a Mineral Admixture in Portland Cement Concrete. Annual Book of ASTM Standards, ASTM, Philadelphia, USA. 